\title{
Air Compressor Crankshaft Machining Feasibility
}

\author{
Aditya B. Rajopadhye ${ }^{+*}$ and S. P. Wadkar ${ }^{\dagger}$ \\ †Department of Mechanical Engg., MIT College Of Engineering,Pune,India \\ Accepted 02 March 2016, Available online 15 March 2016, Special Issue-4 (March 2016)
}

\begin{abstract}
Air compressor plays a vital role in supplying compressed air to air circuits in any vehicle systems. Many a times such compressors are run on exhaust gas pressure which drives the turbine which drives the compressor. Crankshaft is integral part of compressor. Earlier the supplier was suffering from machining issue in the grinding of crankshaft of single cylinder reciprocationg compressor. It is not at all recommended that the rotating part having poor surface finish or having burn mmarks on it.This leads to fatigue failure. Hence to resolve the problem of burn marks and loading of grinding machine, the process and design is modified. Balancing of crankshaft is also insured after the changes. In this paper the description of effective manufacturing of compressor crankshaft along with sequence of machining operation is given. The new modified design with its manufacturing and design advantages are given.
\end{abstract}

Keywords: Crankshaft machining, grinding of crankshaft, compressor crankshaft

\section{Introduction}

${ }^{1}$ Air Compressors are work absorbing devices which are used for increasing pressure of fluid at the expense or work done on fluid. The compressors used for compressing air are called air compressors. Compressors are invariably used for all applications requiring high pressure air. Some of popular applications of compressor are, for driving pneumatic tools and air operated equipments, spray painting, compressed air engine, supercharging surface cleaning, refrigeration and air conditioning, chemical industry etc. compressors are supplied with low pressure air (or any fluid) at inlet which comes out as high pressure air (or any fluid) at outlet. Work required for increasing pressure of air is available from the prime mover driving the compressor. Generally, electric motor, internal combustion engine or steam engine, turbine etc. are used as prime movers. Compressors are similar to fans and blowers but differ in terms of pressure ratios. Fan is said to have pressure ratio up to 1.1 and blowers have pressure ratio between 1.1to 4 while compressors have pressure ratios more than 4 .

Crankshaft is the key component in air compressor, which transmits power from prime mover to the piston.

This particular compressor is used in JCB machines so as to supply compressed air to cooling circuits of driver cabin room. The problem arised during grinding processs of crankshaft which is ressolved. The compressor used for analysis is single cylinder reciprocating compressor.

\section{Problem Statement}

There was a problem in grinding the web portion of crankshaft of compressor. There were burn marks on web along with loading of grinding wheel.

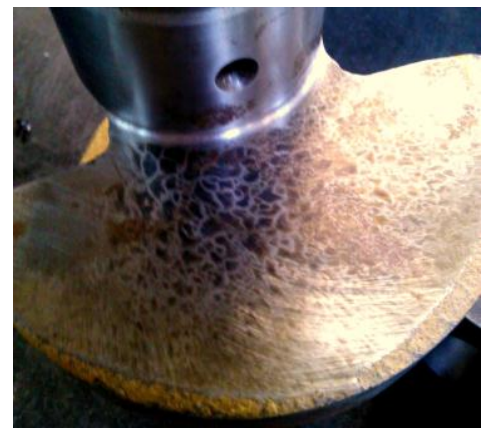

Fig 1. Burn marks on crankshaft

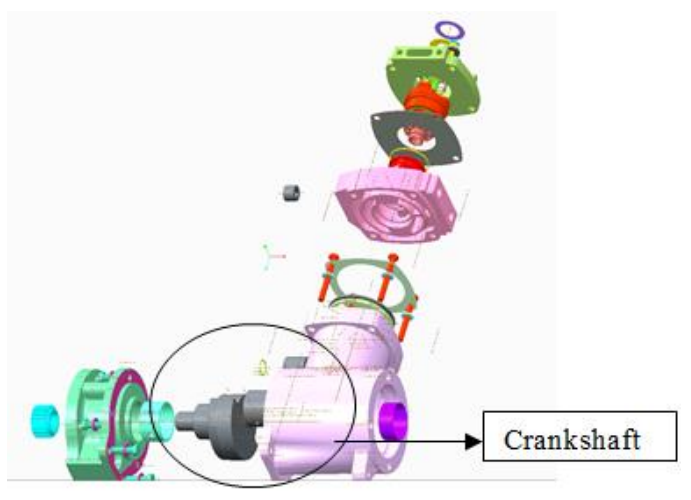

Fig2.CompressorAssembly 


\section{Crankshaft Terminology}

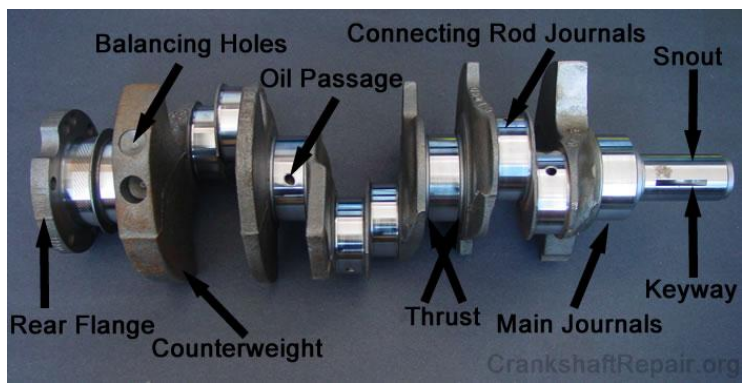

Fig 3.Crankshaft terminology

\section{Manufacturing of Crankshaft}

\subsection{Effective Manufacturing procedure}

Generally for low duty applications generally crankshafts are made by 'Casting' process while heavy duty crankshafts are made by 'Forging' process. Steps involved in Manufacturing of Crankshaft.-

1) Casting- A casted crankshaft is made from molten iron or steel and simply poured into a mold. The raw casting is then rough machined so that it can be ground to its finish dimensions and then balanced. These types of crankshafts are relatively inexpensive. Since casted crankshafts contain flakes of graphite flakes, these crankshafts often have a grey visual appearance. These are usually made from cope and drag type equipments. 2) Facing- As very poor surface finish obtained in casting the Facing operation is carried out on end faces of Castings. This makes end faces completely flat, which makes operator to take reference surface for further machining.

3) Oil Hole Drilling-The oil holes are drilled on the crankshaft with the help advanced of drilling machines. These holes permit the lubricating oil to flow through the main journal and bearings.

4) Turning and Lathe Operations- This is one of the most critical steps in manufacturing of crankshafts. Webs and counterweights are turned by using Lathe.

5) Grinding: The web,crankpin,Main journals are grinded in order to get desired level of Surface finish

6) Milling-Milling operation is performed on the end face of crankshaft to fit clutch assembly.

7) Chamfering and polishing- End surfaces of oil holes are generally chamfered in order to remove the burr and whole crankshaft is polished with the help of polishing belts (generally grit size 400).While polishing the oil holes must be closed with the help of plugs to avoid particle inclusions in oil holes which may restrict the flow of oil through passages.

8) Balancing and Inspection- The crankshaft manufactured must be checked thoroughly and balanced in Static as well as dynamic conditions.Either the weights should be added or to be subtracted from the counterweights to bring the crankshaft in balanced condition.

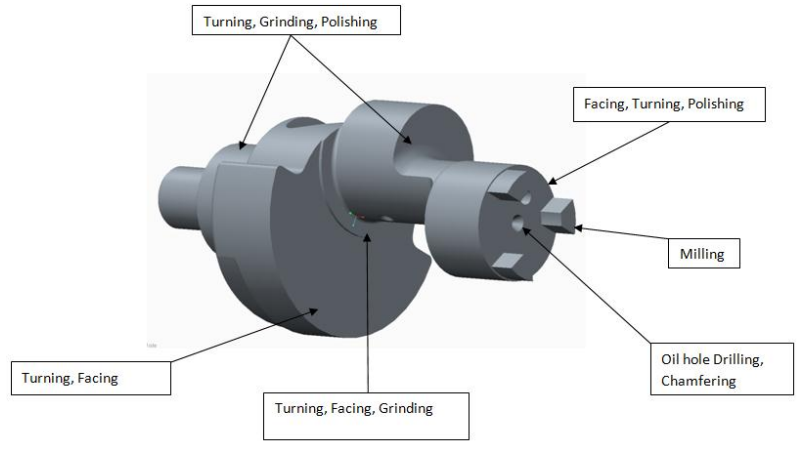

Fig.4 Crankshaft manufacturing processes

\subsection{Crankshaft manufacturing operations}

The Crankshaft shown below is manufactured as per the sequence.

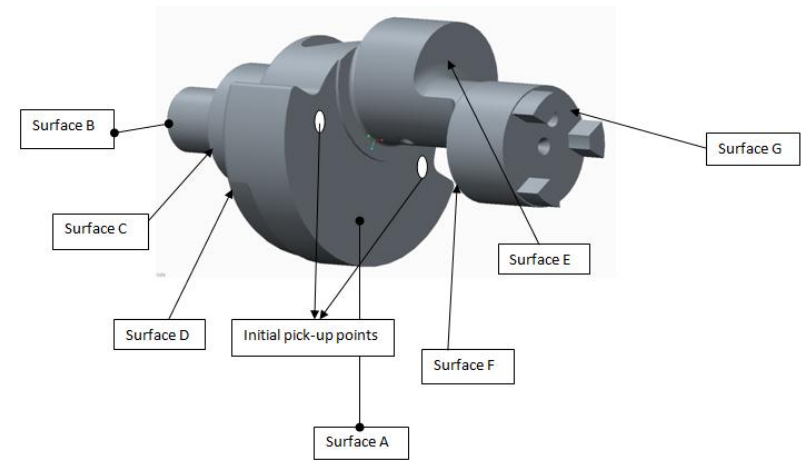

Fig 5.Machining sequence of crankshaft

Generally Crankshaft is manufactured by the sequence as shown in above fig Step-1) Step 1 consist of picking initial reference points on castings as per the casing drawing on a surface

A.

Step-2) After picking initial reference points end surface $B$ is machined first as per the design Step-3) After machining the end surface B , At exact distance from surface $B$, Surface A is machined. Generally turning, facing are the operations carried on surface

\section{A.}

Step-4) With respect to reference surface A,faces $\mathrm{C}, \mathrm{D}, \mathrm{E}, \mathrm{F}, \mathrm{G}$ are to be marked and machined Step-5) Step5 is the crucial stage in manufacturing of crank. This step includes oil hole drilling. Oil holes are drilled as per the drawing. Step-6) Step 6 includes web cutting on the surface G.The web cutting operation is done so as to fit clutch and gear assembly. Step7) Step 7 is the step of crankshaft Grinding. In this process Crankpin is grinded to desired surface finish value.

Step8) The finished crankshaft is checked for quality and sent to further aseembly 


\section{Solution to the Problem}

The grinding is done as the finishing process on crankshaft after turning. Earlier this includes grinding of web, crankpin and journals of crankshaft. But there's no need to grind the whole counterweight surface as this causing the grinding wheel to load along with wear and tear of the wheel .This loading of wheel produces burn marks on work piece as shown. The fillet radius is provided in order to reduce grinding work and rest of web can be easily machined by turning operation.

On each journal, where the bearing surface meets the counterweight, there is a radius or rolled fillet. Although small and typically measured with a radius gauge, this area adds a great deal of strength to the crankshaft.

Thus the design is modified.

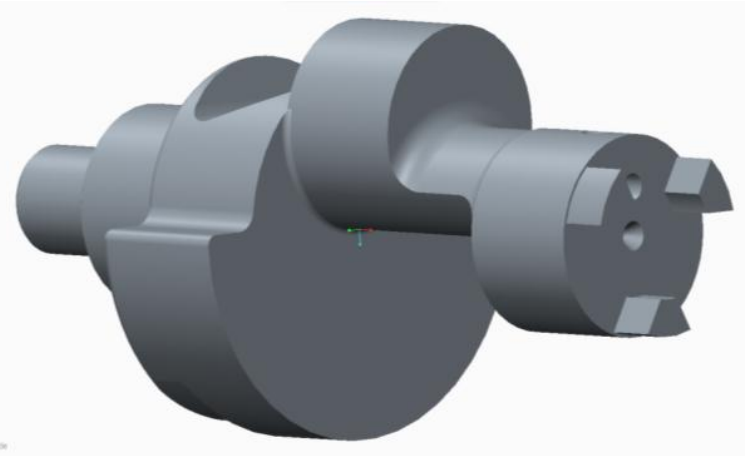

Fig 6. Initial Crankshaft Design

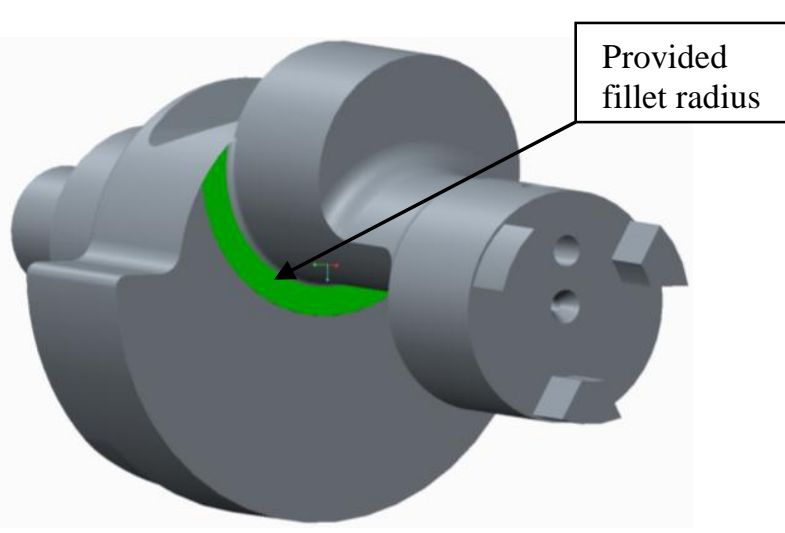

Fig 7. Modified Crankshaft Design

\section{Conclusion}

Advantages of New design Providing fillet radius has mainly 2 advantages over the old design are stated below Manufacturing Advantages. In earlier design the web of the Crankshaft is grinded completely. This effect in burn marks on the web and unbalancing of crankshaft. But in modified design after providing the fillet radius at the joining of crankpin and counterweights reduces effective area of grinding. The load on grinding wheel is reduced .No burn marks are observed as no grinding is applied on that surface.This helps operator in saving his power, money and time.

\section{Design Advantages}

Rotating components are prone to fatigue. Poor surface conditions lead to fatigue failure. Providing fillet radius helps in good surface finish on web surface. Thrust surface of the crankshaft is what prohibits excessive endplay. This provides more thrust surface. The unbalanced force on crankshaft is reduced from $60 \mathrm{gms}$ to $31.75 \mathrm{gms}$ and overall reduction in the weight of crankshaft is just $0.01 \%$.The centre of Gravity of is also changed by $0.01 \%$.So it is concluded that providing small amount of fillet radius does not vary the parameters in that much extent though it is providing benefit in all other aspects like balancing, surface finish, etc.

\section{References}

Advanced Engine technology by Heinz Heisler- Arnold Publications.

Manufacturing processes 2 by A.K.Chattopadhyay, IIT Kanpur Engine Layout configurations and basic mechanics-Report by Mr.N.V.Marathe,ARAI,Pune

The Crank train -Report by Mr. S.S.Ramdasi, ARAI-Pune

Abrasive processes -Module 5 by IIT, Kharagpur

http://crankshaftrepair.org/grinding/

http://www.epieng.com/piston_engine_technology/cranksh aft_design_issues.htm

http://newengineeringpractice.blogspot.in/2014/10/manuf acturing-process-of-crankshafts.html 